Indonesian Journal of Electronics and Instrumentation Systems (IJEIS)

Vol.9, No.2, October 2019, pp. 107 118

ISSN (print): 2088-3714, ISSN (online): 2460-7681

DOI: https://doi.org/10.22146/ijeis.34132

\title{
Sistem Pengukuran Nitrogen, Fosfor, Kalium Dengan Local Binary Pattern Dan Analisis Regresi
}

\author{
Muhammad Miftahul Amri*1, Raden Sumiharto ${ }^{2}$ \\ ${ }^{1}$ Prodi Elektronika dan Instrumentasi, FMIPA UGM, Yogyakarta, Indonesia \\ ${ }^{2}$ Departemen Ilmu Komputer dan Elektronika, FMIPA UGM, Yogyakarta, Indonesia \\ e-mail: *11 muhammadma97@gmail.com,$~{ }^{2}$ r_sumiharto@ugm.ac.id
}

\begin{abstract}
Abstrak
Unsur hara Nitrogen, Fosfor, dan Kalium (NPK) adalah unsur makro yang penting untuk perkembangan tanaman padi. Unsur NPK merupakan parameter untuk menghitung dosis pemupukan. Pengukuran unsur hara saat ini melalui uji laboratorium membutuhkan waktu yang relatif lama sehingga dibutuhkan suatu rancangan sistem yang dapat mempercepat proses pengukuran dan memberikan rekomendasi pemupukan yang tepat.

Makalah ini mengusulkan rancangan sistem menggunakan Local Binary Pattern (LBP) dan Analisis Regresi berbasis android untuk mengukur kadar unsur hara pada tanah dan memberikan rekomendasi pemupukan berdasarkan formula LPT Bogor. Sampel citra tanah diambil dari tanah persawahan di Daerah Istimewa Yogyakarta. Sistem pengukuran dilakukan dengan ekstraksi fitur tekstur LBP dari citra tanah yang telah melalui tahap pra pengolahan. Hasil ekstraksi tersebut kemudian dianalisis dengan menggunakan Regresi Linear Berganda. Pada penelitian ini, persamaan hasil Regresi Linear Berganda digunakan untuk menghitung unsur NPK.

Hasil pengujian menunjukkan bahwa sistem yang diusulkan dapat melakukan pendeteksian kadar Unsur Hara NPK pada Tanah Persawahan di Daerah Istimewa Yogyakarta serta memberikan saran pemupukan berdasarkan formula LPT Bogor dengan akurasi pendeteksian rata-rata 70,65\% (N 94,98\%, P 50,84\%, dan K 66,14\%). Akurasi tersebut didapat dari pengambilan citra pada ketinggian optimal $70 \mathrm{~cm}$ dan sudut optimal $0^{\circ}$ terhadap permukaan tanah serta rata-rata waktu pemrosesan selama 0,61 detik.
\end{abstract}

Kata kunci-unsur hara tanah, ekstraksi fitur tekstur, Regresi Linear Berganda, waktu, akurasi

Abstract
Nitrogen, Phosphorus and Potassium (NPK) are macro elements that important for the paddy development. NPK is a parameter that used for calculating fertilizer dosage. Current NPK measurement through laboratory requires a relatively long time, so we design a new system that can speed up the process and provide correct fertilizer dosage recommendations.

This paper proposes an android based system using Local Binary Pattern (LBP) and Regression Analysis to measure soil nutrients and provide fertilizer dosage recommendations based on the LPT Bogor's formula. Samples of soil image taken from rice fields in Special Region of Yogyakarta. The measurement is processed by extracting LBP features from the soil image that has through the pre-processing stage. The extraction results were then analyzed using Multiple Linear Regression (MLR). The equation results from MLR is used to calculate $N P K$.

The results show that the proposed system can detect NPK levels in paddy fields in Yogyakarta and provide fertilization dosage with an average detection accuracy of $70.65 \%(N$ $94.98 \%, P 50.84 \%$, and $K 66.14 \%)$. The accuracy was obtained from the image taking at an optimal height of $70 \mathrm{~cm}$ and optimal angle of $0^{\circ}$ to the ground surface. The average processing time is 0.61 seconds.

Keywords - soil nutrient, texture feature extraction, multiple linear regression, time, accuracy

Received March 21 $1^{\text {th }}, 2018 ;$ Revised January 16 ${ }^{\text {th }}, 2019 ;$ Accepted October $7^{\text {th }}, 2019$ 


\section{PENDAHULUAN}

Kehidupan manusia tidak dapat dipisahkan dari sektor pertanian. Ketersediaan makanan sebagai kebutuhan pokok manusia tergantung pada keberhasilan sektor pertanian. Produksi pertanian masih bergantung pada ketersediaan lahan sebagai media tanam. Media yang baik dapat menyediakan unsur hara dalam jumlah yang cukup sehingga dapat mendukung produktivitas tanaman. Namun, luas penggunaan lahan pertanian terus mengalami penurunan. Pada tahun 2016 hingga 2017, D.I. Yogyakarta mengalami penurunan luas penggunaan lahan pertanian sebesar $0,96 \%$ [1]. Penurunan luas penggunaan lahan pertanian tersebut akibat pesatnya pertumbuhan penduduk dan sektor industri yang mendorong terjadinya alih fungsi lahan pertanian menjadi perumahan dan pabrik. Hal tersebut berdampak pada penurunan ketersediaan hasil produksi pertanian untuk mencukupi kebutuhan pangan. Upaya yang dapat dilakukan salah satunya adalah dengan memaksimalkan potensi lahan yang ada dengan menjaga kandungan unsur hara yang tersedia cukup untuk mendukung produktivitas tanaman.

Deteksi unsur hara penting dilakukan untuk mengetahui kandungan unsur hara yang tersedia di dalam tanah. Penerapan teknologi dapat dilakukan untuk meningkatkan produktivitas sektor pertanian salah satunya untuk mengetahui kadar unsur Nitrogen, Fosfor dan Kalium (NPK) dalam tanah. NPK merupakan unsur hara makro terpenting yang diperlukan oleh tanaman. Unsur hara NPK umumnya menjadi parameter pemupukan Tanaman Padi. Saat ini, kadar NPK yang terkandung dalam tanah dapat diketahui dengan menggunakan spectrophotometer dan analisis laboratorium. Namun, penggunaan spectrophotometer dan analisis laboratorium untuk mengetahui kadar NPK yang terkandung dalam tanah membutuhkan biaya yang relatif tinggi, waktu yang relatif lama, serta akses petani yang sulit pada laboratorium sehingga membuat petani cenderung enggan melakukan pengukuran unsur hara NPK dan melakukan pemupukan dengan dosis sesuai pengalaman dan kebiasaan masingmasing yang belum tentu tepat.

Perkembangan teknologi dan ilmu pengetahuan seperti pengolahan citra digital (PCD) dan teknik pengolahan data saat ini telah memungkinkan untuk melakukan prediksi kadar unsur NPK yang terkandung dalam tanah dan diharapkan dapat mengatasi kelemahan yang muncul dalam penggunaan spectrophotometer dan analisis laboratorium serta mendorong petani untuk melakukan pemupukan berdasarkan pengukuran unsur hara NPK secara mandiri. Pada penelitian ini, metode yang digunakan adalah metode ekstraksi fitur tekstur Local Binary Pattern (LBP) dipadukan dengan Analisis Regresi Linear Berganda. Analisis Regresi memiliki karakter sederhana dan ringan pada komputasinya [2], serta bersifat invarian terhadap perubahan kuat cahaya (intensity) dan derajat penerangan (brightness) pada objek yang sama karena merupakan ukuran intensitas relatif suatu piksel dengan intensitas piksel di sekitarnya [3]. Penelitian untuk mendeteksi tingkat kelembaban pada tanah sawah dengan metode Histogram of Oriented Gradients (HOG), k-Nearest Neighbor (k-NN) dan Multilayer Perceptron (MLP) telah berhasil dilakukan [4], namun penelitian tersebut belum mampu mendeteksi kadar unsur NPK. Oleh karena itu, dalam penelitian ini diusulkan sebuah sistem untuk memprediksi kadar unsur NPK dengan memanfaatkan metode LBP dan metode Analisis Regresi.

\section{METODE PENELITIAN}

\subsection{Analisis Kebutuhan Sistem}

Rancangan sistem pada penelitian ini ditujukan agar sistem dapat mendeteksi unsur hara NPK menggunakan algoritma LBP dan analisis regresi serta memberikan rekomendasi pemupukan berdasarkan formula dari LPT Bogor. Sistem ini disusun pada platform smartphone android. Citra digital diambil dari tanah areal persawahan dengan menggunakan kamera smartphone beresolusi minimal 460 x 680 . Hasil pengambilan citra kemudian disusun dalam 
bentuk array kemudian dilakukan proses pra pengolahan. Hasil dari pra pengolahan diekstraksi fitur teksturnya dengan menggunakan algoritma LBP yang selanjutnya dilakukan normalisasi. Proses tersebut dilakukan dengan menggunakan aplikasi MATLAB pada komputer. Hasil normalisasi diperiksa distribusi datanya terhadap hasil uji lab. Dilakukan transformasi data (bila distribusi data non-linear namun dapat dilinearisasi). Hasil pada proses tersebut digunakan untuk mencari persamaan dengan menggunakan analisis regresi. Analisis regresi yang dipilih sesuai dengan distribusi data, dalam hal ini Regresi Linear Berganda. Keluaran dari proses tersebut adalah persamaan regresi. Proses tersebut dilakukan dengan menggunakan program SPSS pada komputer. Hasil persamaan regresi digunakan untuk menghitung nilai unsur NPK pada data uji dengan memanfaatkan variabel hasil normalisasi LBP citra data uji. Proses tersebut dilakukan dengan menggunakan aplikasi android yang telah di-install pada smartphone. Proses pembuatan aplikasi dilakukan dengan Android Studio pada komputer.

\subsection{Proses Pengambilan Sampel}

Pengambilan sampel dilakukan pada 10 lahan Padi yang tersebar di D.I. Yogyakarta secara acak di antara pukul 09.00-13.00 WIB agar mendapat pencahayaan pada rentang 7.500 lux - 25.000 lux. Lokasi pengambilan sampel tercantum pada Tabel 1. Proses pengambilan citra dimulai dari membersihkan permukaan tanah dari kotoran untuk menghindari gangguan pada citra (noise). Kemudian dilakukan penghilangan top soil sedalam 10-15 cm dari permukaan tanah [5]. Selanjutnya dilakukan pengambilan citra dengan variasi ketinggian kamera terhadap sampel tanah pada rentang $30-110 \mathrm{~cm}$ (interval $20 \mathrm{~cm}$ ) dan sudut kamera terhadap sampel tanah pada rentang $(-30)-30^{\circ}$ (interval $10^{\circ}$ ) menggunakan tripod, waterpass, dan busur. Setelah dilakukan pengambilan citra, tanah diambil sebanyak \pm 500 gram untuk diuji di laboratorium tanah Fakultas Pertanian UGM.

Tabel 1 Lokasi pengambilan sampel

\begin{tabular}{|l|c|l|c|}
\hline \multicolumn{1}{|c|}{ Daerah } & \multicolumn{1}{|c|}{ Koordinat } & \multicolumn{1}{c|}{ Daerah } & \multicolumn{1}{c|}{ Koordinat } \\
\hline Guwosari & $7^{\circ} 51^{\prime} 35.7^{\prime \prime} \mathrm{S} 110^{\circ} 18^{\prime} 29.7^{\prime \prime} \mathrm{P}$ & Pakem & $7^{\circ} 40^{\prime} 08.0^{\prime \prime} \mathrm{S} 110^{\circ} 25^{\prime} 14.6^{\prime \prime} \mathrm{E}$ \\
\hline Cangkringan & $7^{\circ} 37^{\prime} 47.2^{\prime \prime} \mathrm{S} 110^{\circ} 25^{\prime} 31.7^{\prime \prime} \mathrm{E}$ & Palagan & $7^{\circ} 43^{\prime} 32.8^{\prime \prime} \mathrm{S} 110^{\circ} 22^{\prime} 29.0^{\prime \prime} \mathrm{E}$ \\
\hline Godean & $7^{\circ} 46^{\prime} 36.4^{\prime \prime} \mathrm{S} 110^{\circ} 19^{\prime} 18.6^{\prime \prime} \mathrm{E}$ & Pogung & $7^{\circ} 45^{\prime} 29.6^{\prime \prime} \mathrm{S} 110^{\circ} 22^{\prime} 29.0^{\prime \prime} \mathrm{E}$ \\
\hline Kalasan & $7^{\circ} 46^{\prime} 17.7^{\prime \prime} \mathrm{S} 110^{\circ} 27^{\prime} 07.9^{\prime \prime} \mathrm{E}$ & Sewon & $7^{\circ} 52^{\prime} 53.9^{\prime \prime} \mathrm{S} 110^{\circ} 22^{\prime} 06.2^{\prime \prime} \mathrm{E}$ \\
\hline Imogiri & $7^{\circ} 55^{\prime} 42.5^{\prime \prime} \mathrm{S} 110^{\circ} 24^{\prime} 50.0^{\prime \prime} \mathrm{E}$ & Taman Tirto & $7^{\circ} 49^{\prime} 38.1^{\prime \prime} \mathrm{S} 110^{\circ} 19^{\prime} 10.7^{\prime \prime} \mathrm{E}$ \\
\hline
\end{tabular}

\subsection{Rancangan Sistem}

Rancangan keseluruhan sistem terdiri dari perangkat keras dan perangkat lunak. Pada perancangan perangkat keras terdapat kamera smartphone yang terpasang pada tripod yang telah dirancang dan mengarah tepat ke titik tengah dari sampel tanah. Ketinggian dan sudut pengambilan citra pada tripod dapat diubah. Untuk meminimalisir subjektifitas dan meningkatkan keakuratan pengambilan citra, tripod ditambahkan dengan waterpass 2 axis (pitch dan roll) dan dibuat agar tidak bisa bergerak pada sumbu yaw (dimatikan). Meteran dan busur digunakan untuk mengukur ketinggian dan sudut. Luxmeter digunakan untuk mengukur tingkat pencahayaan lingkungan. Proses pada perangkat lunak terdiri dari beberapa algoritma program yang digunakan untuk pra pengolahan, ekstraksi fitur tekstur, analisis regresi, hingga pendeteksi unsur hara, dan pemberian saran pemupukan. Diagram blok dari sistem tercantum pada Gambar 1. 


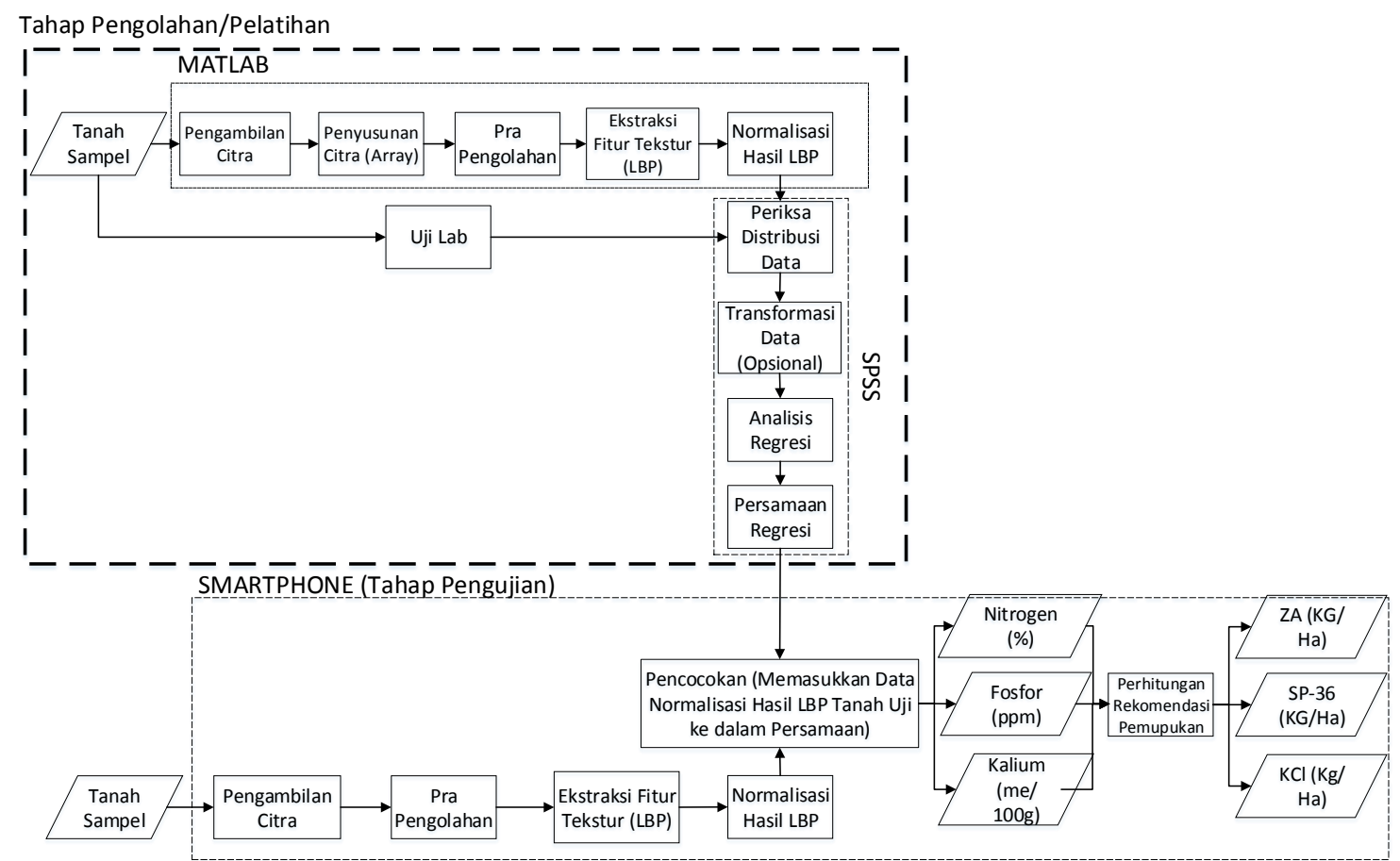

Gambar 1 Diagram blok sistem

\subsubsection{Perancangan Perangkat Keras}

Perangkat keras yang digunakan meliputi Komputer (Intel Core I5-7200U, 8192MB

RAM, Sandisk 128GB SSD, VGA NVIDIA Geforce 930MX \& Intel HD Graphics 620 Display), tripod dengan waterpass dan kamera smartphone dengan sensor warna RGB yang beresolusi minimal 640 x 480, dalam hal ini berupa Samsung Galaxy S6 Edge. Ilustrasi rancangan perangkat keras tercantum pada Gambar 2.
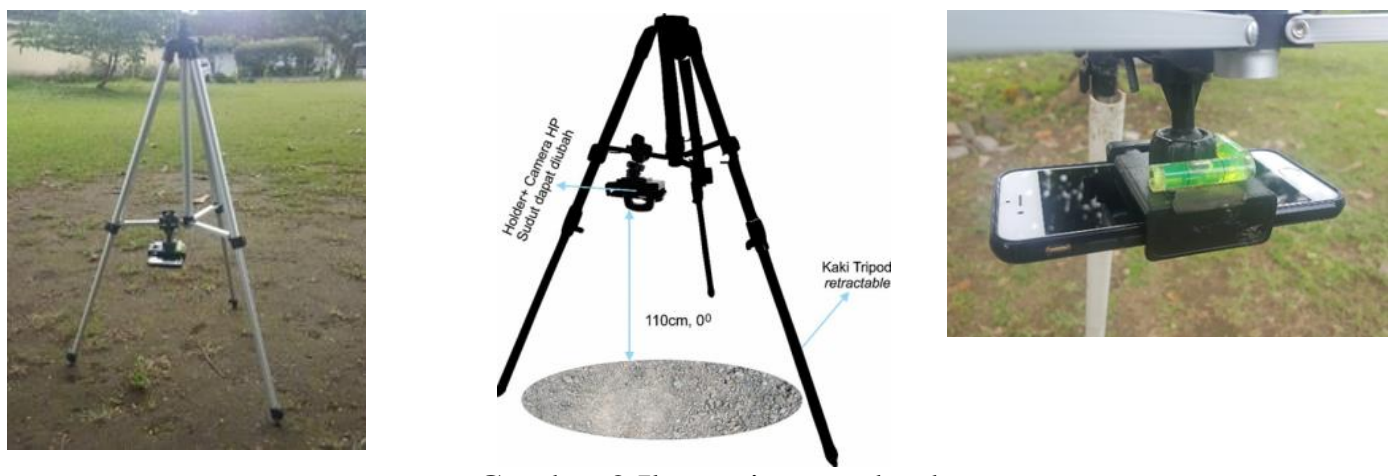

Gambar 2 Ilustrasi perangkat keras

\subsubsection{Perancangan Perangkat Lunak}

Tahap perancangan perangkat lunak terdiri dari enam bagian, meliputi: akuisisi citra, pra pengolahan, ekstraksi fitur tekstur, analisis data, pencocokan atau klasifikasi data, dan pemberian saran pemupukan. Perangkat lunak yang digunakan meliputi MATLAB R2017a, SPSS v23, Android Studio 3.0.1, OpenCV 3.1.0, Android ICS 4.0 atau lebih, dan Windows 10 64 Bit. 


\subsubsection{Akuisisi Citra}

Tahap akuisisi citra adalah tahap pengambilan citra tanah dengan menggunakan kamera dalam format RGB dan berukuran 2448 x 2448 pixel. Ada berbagai macam permasalahan yang membutuhkan citra sebagai masukan atau input sistem dikarenakan keterbatasan manusia dalam memproses suatu fungsi matematis maupun algoritma pendukung didalamnya [5]. Jumlah citra yang akan diakuisisi adalah sebanyak 350 citra, meliputi pengambilan citra pada sepuluh lokasi yang tercantum pada Tabel 1 dengan variasi ketinggian antara $30 \mathrm{~cm}-110 \mathrm{~cm}$ (interval $20 \mathrm{~cm}$ ) dan sudut antara $-30^{\circ}-30^{\circ}$ (interval $10^{\circ}$ ). Dari 350 data citra, digunakan 280 data sebagai data latih, dan 70 data sebagai data uji.

\subsubsection{Pra Pengolahan}

Pra pengolahan citra merupakan sebuah proses yang dilakukan untuk mendapatkan kualitas yang lebih baik daripada citra sebelumnya [6]. Terdapat empat tahap pra pengolahan yang dilakukan. Tahap pertama adalah melakukan crop atau memangkas citra pada titik tengahnya menjadi ukuran 640 x 480 pixel. Ukuran 640 x 480 pixel menyebabkan proses komputasi citra menjadi lebih cepat, namun tanpa mengurangi performa sistem secara signifikan. Tahap kedua adalah melakukan konversi citra yang pada awalnya berformat RGB menjadi grayscale. Tahap selanjutnya adalah melakukan penyetaraan histogram dengan menggunakan metode Histogram Equalization kemudian dilakukan proses tapis dengan menggunakan metode $2 D$ Convolution Filter. Tapis Konvolusi 2D inilah yang banyak digunakan pengolahan citra digital [7]. Diagram alir tahap pra pengolahan tercantum pada Gambar 3.

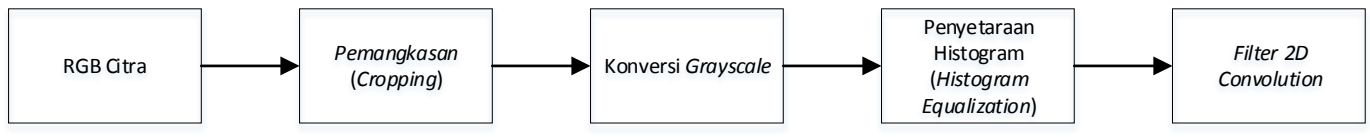

Gambar 3 Diagram alir tahap pra pengolahan

\subsubsection{Ekstraksi Fitur Tekstur}

Citra tanah diekstraksi teksturnya menggunakan Local Binary Pattern (LBP). Prinsip kerja dari LBP adalah, nilai dari setiap pixel citra tanah dibandingkan dengan 8 tetangganya dan dikodekan ke dalam 8-bit, untuk mengganti nilai pixel lama dengan nilai desimal dari pengkodean 8 bit tersebut. Sehingga didapatkan 256 ciri hasil ekstraksi LBP.

\subsubsection{Analisis Data}

Sesuai Gambar 3, digunakan data hasil uji lab sebagai variabel tergantung pada regresi. Masukan berupa frekuensi nilai pixel data (0-255) hasil ekstraksi LBP disusun pada tabel sebagai variabel bebas untuk mendapatkan persamaan regresi.

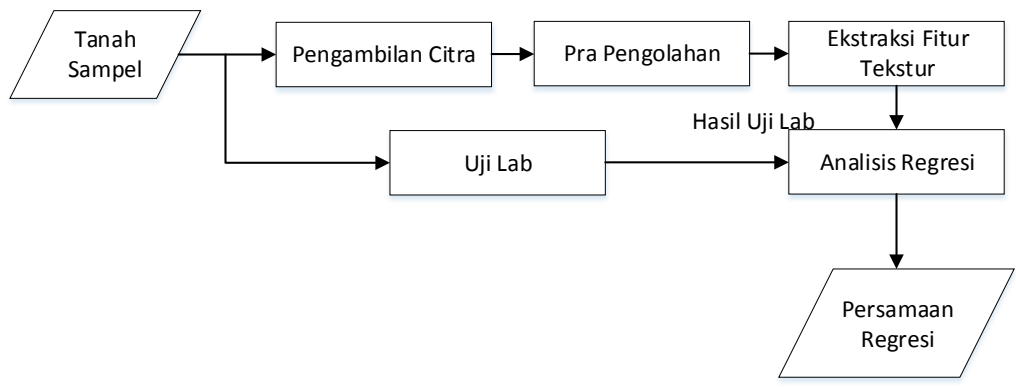

Gambar 4 Diagram analisis sistem 
Pada tahap analisis data, nilai hasil ekstraksi LBP yang telah dinormalisasi diperiksa distribusi datanya terhadap referensi nilai $\mathrm{N}$, P, dan $\mathrm{K}$ hasil cek laboratorium, dilakukan transformasi (bila perlu), dan dilakukan regresi. Diagram alir analisis regresi tercantum pada Gambar 5.

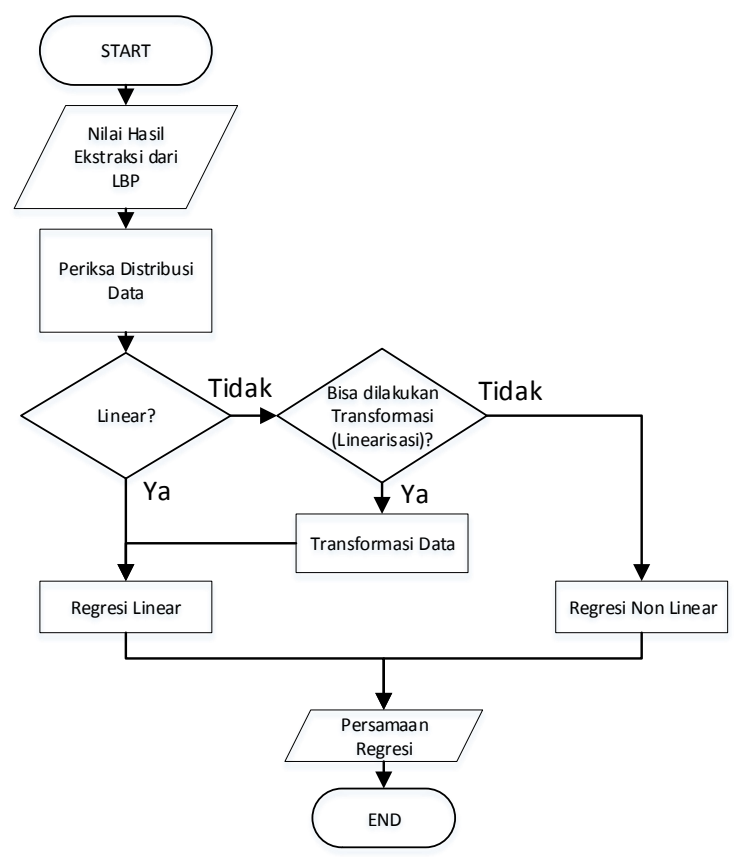

Gambar 5 Diagram alir analisis regresi

Rata-rata Model Summary hasil pemeriksaan kurva estimasi dari 256 variabel bebas hasil normalisasi LBP terhadap variabel bergantung NPK pada penelitian ini tercantum pada Tabel 2 menunjukkan bahwa meskipun tidak ada distribusi absolut (nilai R dan R Square $=1$ ), nilai R Square pada distribusi eksponensial $(0,314)$ paling besar dibanding dengan distribusi model lain dan nilai signifikansi dibawah $0.05(0,001)$ sehingga dapat disimpulkan bahwa distribusi data menunjukkan kecenderungan terhadap distribusi eksponensial. Koefisien Determinasi (R) merupakan nilai yang digunakan untuk mengukur besarnya kontribusi seluruh variabel bebas (X) yang ada di dalam model terhadap variasi (naik atau turunnya) variabel bergantung (Y) [8]. Metode Curve Estimation (Estimasi Kurva) digunakan untuk melihat pola atau model hubungan antar variabel yang diuji. Terdapat banyak pola di antaranya linear, kuadratik, dan sebagainya [9]. Data eksponensial merupakan data non linear. Data non linear ini dapat dilinearkan dengan cara transformasi. Terdapat beberapa rumus transformasi data berdasarkan tipe distribusi data tersebut. Rumus transformasi data untuk data eksponensial (Persamaan (1)) tercantum pada Persamaan (2).

$$
\begin{gathered}
Y=\alpha X^{\beta} \\
\ln (Y)=\ln (\alpha)+\beta[\operatorname{Ln}(X)]
\end{gathered}
$$

Nilai $\mathrm{X}$ dan $\ln (\mathrm{Y})$ kemudian diregresikan secara linear sehingga diperoleh suatu persamaan dengan 256 variabel. Regresi linear yang dilakukan adalah regresi linear berganda karena sistem ini memiliki 256 variabel bebas dari fitur LBP yang telah dinormalisasi $(>1)$ dan 3 variabel bergantung dari nilai unsur NPK. Regresi linear berganda digunakan oleh peneliti jika bermaksud meramalkan bagaimana keadaan (naik-turunnya) variabel bergantung, bila dua atau lebih variabel bebas sebagai faktor prediktor diubah nilainya [10]. Persamaan ini kemudian dimasukkan ke dalam sistem perhitungan yang telah diinstall pada smartphone. 
Tabel 3 Output model summary

\begin{tabular}{|l|r|c|r|r|r|r|r|r|r|}
\hline \multirow{3}{*}{$\begin{array}{l}\text { Equation } \\
\text { Exponential }\end{array}$} & \multicolumn{4}{|c|}{ Model Summary } & \multicolumn{4}{|c|}{ Parameter Estimates } \\
\cline { 2 - 11 } & R Square & $\mathrm{F}$ & df1 & df2 & Sig. & Constant & b1 & b2 & b3 \\
\hline
\end{tabular}

\subsubsection{Pencocokan/Klasifikasi Data}

Pada tahap pencocokan, hasil ekstraksi fitur tekstur LBP dari data uji dimasukkan ke dalam persamaan regresi yang telah dihasilkan pada tahap analisis data. Angka hasil perhitungan persamaan regresi ini menjadi prediksi nilai unsur hara data uji (expected value).

\subsubsection{Pemberian Saran Pemupukan}

Setelah diketahui nilai N, P, dan K pada suatu tanah uji, nilai ini kemudian dimasukkan pada rumus saran pemupukan milik [11] dan ditampilkan. Rumus saran pemupukan [11] tercantum pada Persamaan (3).

$$
\begin{gathered}
\text { Kadar ZA }(K G)=(-1000 *(\text { KADAR N }(\%))+220) * 100 / 21 \\
\text { Kadar SP }-36(K G)=(-3 *(\text { KADAR P2O5 }(\text { ppm }))+225) * 100 / 36 \\
\text { Kadar KCl }(K G)=(-0,5 *(\text { KADAR K } 20(p p m))+195) * 100 / 60
\end{gathered}
$$

\subsection{Pengujian Sistem}

Setelah sistem selesai dibuat, dilakukan pengujian dengan sampel tanah uji. Rencana pengujian pada sistem meliputi pengujian akurasi dan kecepatan komputasi sistem.

Pengujian akurasi diukur dengan menghitung nilai mean absolute percentage error (MAPE). MAPE merupakan nilai persentase absolut dari rata-rata MAPE antara nilai hasil lab $\left(t_{i}\right)$ dengan nilai prediksi sistem $\left(y_{i}\right)$. Nilai MAPE dapat dihitung dengan Persamaan (4).

$$
\text { MAPE }=\frac{1}{n} \sum_{i=1}^{n}\left(t_{i}-y_{i}\right) \times 100 \%
$$

Pengujian kecepatan komputasi dimulai saat citra terambil hingga prediksi nilai unsur NPK keluar. Perhitungan waktu komputasi dilakukan dengan cara memberikan fitur TAG LOG pada program Android Studio. Waktu komputasi didapatkan dengan pengurangan waktu pada saat TAG LOG 'finish' muncul terhadap waktu pada saat TAG LOG 'start' muncul.

\subsection{Perhitungan Rekomendasi Pemupukan}

Hasil prediksi unsur nilai $\mathrm{K}$ pada tahap pengujian perlu dikonversi dahulu menjadi satuan ppm. Konversi dilakukan karena data referensi dari laboratorium memiliki satuan me/100g, sedangkan rumus [11] menggunakan satuan ppm. Rumus konversi me/100g menjadi ppm tercantum pada Persamaan (5).

$$
1 \frac{m e}{100 g}=\left(1 x \frac{B a}{V} * 10\right) p p m
$$

dengan:

$B a=$ berat atom

$V=$ elektron valensi atom

Setelah dilakukan konversi satuan pada nilai unsur $\mathrm{K}$, hasil prediksi dari unsur $\mathrm{P}(\mathrm{ppm})$ dan unsur $\mathrm{K}(\mathrm{ppm})$ masing-masing perlu dikonversi terlebih dahulu menjadi nilai $\mathrm{P}_{2} \mathrm{O}_{5}$ dan $\mathrm{K}_{2} \mathrm{O}$. 
Konversi dilakukan karena menurut rumus perhitungan [11], nilai parameter perhitungan unsur $\mathrm{P}$ harus berbentuk $\mathrm{P}_{2} \mathrm{O}_{5}$ dan unsur $\mathrm{K}$ harus berbentuk $\mathrm{K}_{2} \mathrm{O}$. Rumus konversi dari unsur $\mathrm{P}$ menjadi $\mathrm{P}_{2} \mathrm{O}_{5}$ dan dari unsur $\mathrm{K}$ menjadi $\mathrm{K}_{2} \mathrm{O}$ adalah:

$$
\begin{gathered}
P_{2} \mathrm{O}_{5}=P(p p m) * M r P_{2} O_{5} / \mathrm{ArP}_{2} \\
\mathrm{~K}_{2} \mathrm{O}=\mathrm{K}(\mathrm{ppm}) * \mathrm{MrK}_{2} \mathrm{O} / \mathrm{ArK}
\end{gathered}
$$

Mengacu pada rumus [11], maka dilakukan perhitungan dan didapatkan hasil rekomendasi pemupukan dalam satuan $\mathrm{kg} / \mathrm{ha}$.

\section{HASIL DAN PEMBAHASAN}

Pengujian yang dilakukan pada penelitian ini dilakukan untuk mengetahui ketinggian optimal, toleransi perbedaan ketinggian, toleransi perbedaan sudut, pengaruh jumlah sampel latih terhadap akurasi, dan mengukur lama waktu komputasi sistem. Pengujian tahap pertama dari penelitian ini adalah pengujian untuk mengetahui ketinggian optimal dalam mengambil citra yang mampu menghasilkan akurasi paling tinggi. Dalam pengujian ini, digunakan citra dengan sudut $0^{\circ}$ dan variasi ketinggian $30 \mathrm{~cm}, 50 \mathrm{~cm}, 70 \mathrm{~cm}, 90 \mathrm{~cm}$, dan $110 \mathrm{~cm}$ dari kombinasi delapan lokasi secara acak sebagai data sampel, serta citra dari dua lokasi sisanya sebagai data uji. Masing-masing lokasi dengan sepuluh citra, maka total citra yang digunakan adalah 80 citra latih dan 20 citra uji pada masing-masing ketinggian. Digunakan rumus kombinasi untuk melakukan pengujian dengan seluruh kemungkinan kombinasi dua variabel uji agar validitas meningkat. Berdasarkan rumus ${ }_{n} C_{k}=C_{k}^{n}=C(n, k)=\frac{n !}{(n-k) ! k !}$, didapatkan bahwa terdapat 45 kemungkinan kombinasi pada pengujian masing-masing ketinggian.

Berdasarkan hasil pengujian yang tercantum pada Gambar 6, rata-rata akurasi tertinggi $(70,65 \%)$ didapatkan pada ketinggian $70 \mathrm{~cm}$ dengan nilai MAPE hanya mencapai $29,35 \%$. Nilai $\mathrm{N}$ memiliki MAPE yang relatif rendah, yakni hanya berkisar antara 3,87\% hingga 9,07\%. Nilai P memiliki MAPE yang paling tinggi, yakni berkisar antara 50\% hingga 115,18\%. Sedangkan nilai K memiliki MAPE berkisar antara 33,86\% hingga 48,68\%. Digunakan kombinasi data uji Imogiri-Palagan untuk pengujian pada tahap-tahap berikutnya, karena rata- rata hasil MAPE dari kombinasi ini $(29,32 \%)$ paling mendekati rata-rata hasil MAPE keseluruhan sistem $(29,35 \%)$, dengan perbedaan hanya sebesar $0,03 \%$ sehingga hasil dari kombinasi ini dianggap bisa mewakili sistem.

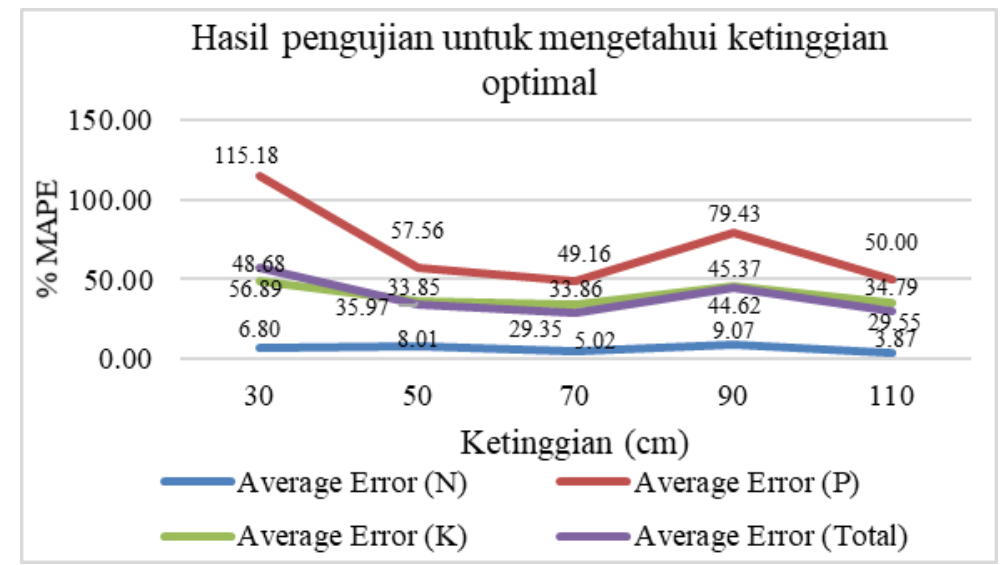

Gambar 6 Grafik pengujian untuk mengetahui ketinggian optimal

IJEIS Vol. 9, No. 2, October 2019: 107 - 118 
Pengujian tahap kedua untuk mengetahui toleransi perbedaan ketinggian terhadap ketinggian optimal $(70 \mathrm{~cm})$. Citra pada sudut $0^{\circ}$ dengan lima variasi ketinggian dari Imogiri dan Palagan sebagai data uji, serta citra pada sudut $0^{\circ}$ dengan ketinggian optimal $(70 \mathrm{~cm})$ dari delapan lokasi sisanya secara acak sebagai data sampel. Masing-masing lokasi dengan sepuluh citra, maka total citra yang digunakan adalah 80 citra latih dan 40 citra uji pada masing-masing lokasi. Sesuai Gambar 7, sistem yang telah terlatih dengan ketinggian $70 \mathrm{~cm}$ dan sudut $0^{\circ}$ masih mampu mengenali data uji dengan ketinggian $50 \mathrm{~cm}$ dengan baik dan tidak mengalami perbedaan MAPE yang signifikan (rata-rata selisih nilai MAPE dengan MAPE pada ketinggian $70 \mathrm{~cm}$ sebesar 3,62\%). Namun, seiring dengan peningkatan selisih ketinggian, tingkat nilai MAPE juga meningkat. Selisih nilai MAPE tertinggi mencapai 25,99\% pada ketinggian $110 \mathrm{~cm}$.

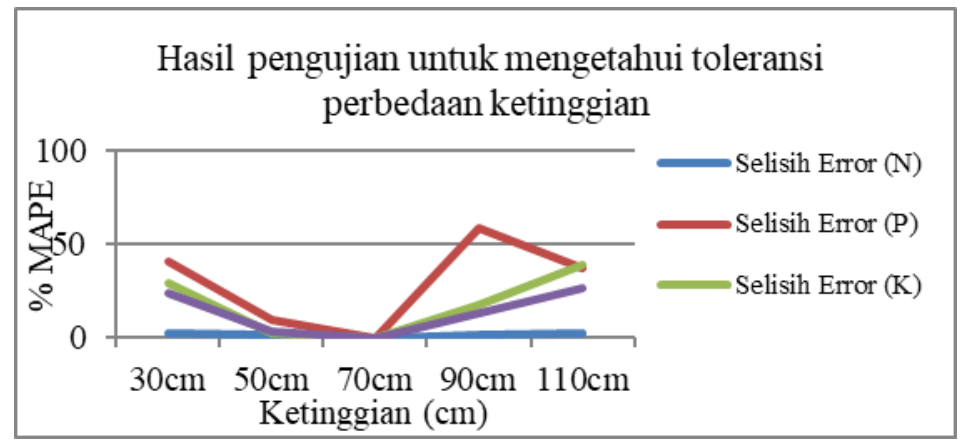

Gambar 7 Grafik pengujian untuk mengetahui toleransi perbedaan keting gian

Pengujian tahap ketiga untuk mengetahui toleransi perubahan sudut terhadap sudut $0^{\circ}$ pada ketinggian optimal. Citra pada sudut $0^{\circ}$ dengan ketinggian optimal $(70 \mathrm{~cm})$ dari 8 lokasi selain Imogiri dan Palagan digunakan sebagai data sampel, serta citra pada variasi seluruh sudut dengan ketinggian optimal $(70 \mathrm{~cm})$ dari Imogiri dan Palagan sebagai data uji. Masing-masing lokasi dengan sepuluh citra, maka total citra yang digunakan adalah 80 citra latih dan 70 citra uji pada masing-masing lokasi. Sesuai Gambar 8, sistem yang telah terlatih dengan ketinggian optimal dan sudut $0^{\circ}$ masih mampu mengenali data uji dengan perbedaan sudut $\pm 10^{\circ}$ dan $\pm 20^{\circ}$ dengan baik dan tidak mengalami perbedaan MAPE yang signifikan (rata-rata selisih nilai MAPE dengan MAPE pada sudut $0^{\circ}$ sebesar 3,13\% dan 6,90\%). Namun, seiring dengan peningkatan selisih sudut, tingkat nilai MAPE juga meningkat. Pada selisih sudut $\pm 20^{\circ}$, rata-rata selisih MAPE 6,90\%. Pada selisih sudut $\pm 30^{\circ}$, rata-rata selisih MAPE 61,58\%.

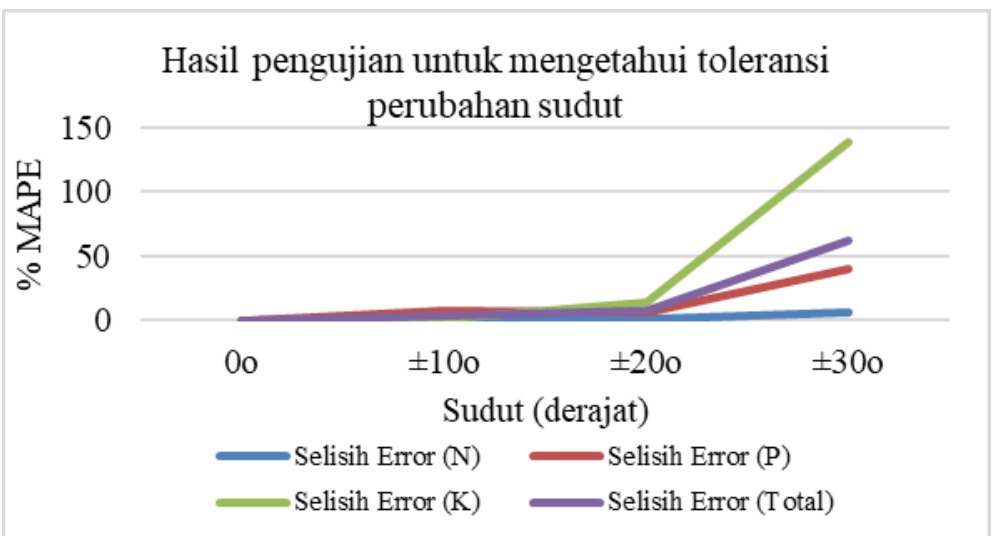

Gambar 8 Grafik pengujian untuk mengetahui toleransi perubahan sudut 
Pengujian tahap keempat untuk mengetahui pengaruh jumlah sampel latih terhadap akurasi dilakukan dengan membandingkan akurasi sistem dengan citra pada ketinggian $70 \mathrm{~cm}$ dan sudut $0^{0}$ dari delapan lokasi selain Imogiri dan Palagan menggunakan variasi antara sepuluh citra, delapan citra, dan enam citra pada masing-masing lokasi. Data uji merupakan citra dari Imogiri dan Palagan dengan sepuluh citra pada masing-masing lokasi. Sesuai pada Gambar 9, jumlah sampel uji berbanding lurus dengan akurasi. Akurasi terendah didapatkan dari 48 data latih (MAPE 61,56\%), kemudian 64 data latih (MAPE 47,83\%), dan paling tinggi didapatkan dari 80 data latih (MAPE 29,35\%), membuktikan bahwa semakin sedikit jumlah sampel latih, maka akurasi juga semakin berkurang. Sebaliknya, jika data latih semakin banyak, maka akurasinya semakin bertambah. Rata-rata MAPE total pada pengujian ini bernilai 48,67\%. nilai $\mathrm{P}$ memiliki rata-rata MAPE paling tinggi, mencapai $48,67 \%$, disusul nilai $\mathrm{K}$ dengan rata-rata MAPE sebesar 87,38\%, dan nilai $\mathrm{N}$ dengan rata-rata MAPE paling rendah, yakni sebesar 9,97\%. Nilai $\mathrm{P}$ memiliki rentang variasi nilai paling tinggi. antara 4,15 - 38,62 ppm $(34,47) \mathrm{ppm}$, kemudian nilai $\mathrm{K}$ dengan rentang variasi nilai $0,29-2,53 \mathrm{me} / 100 \mathrm{~g}(2,24$ $\mathrm{me} / 100 \mathrm{~g})$, dan nilai $\mathrm{N}$ dengan rentang variasi nilai paling rendah $0,17-0,21 \%(0,04 \%)$. Sesuai dengan hasil dari pengujian pertama hingga ke empat, hal ini membuktikan hipotesis bahwa semakin tinggi rentang variasi nilai variabel bergantung membuat akurasi semakin rendah.

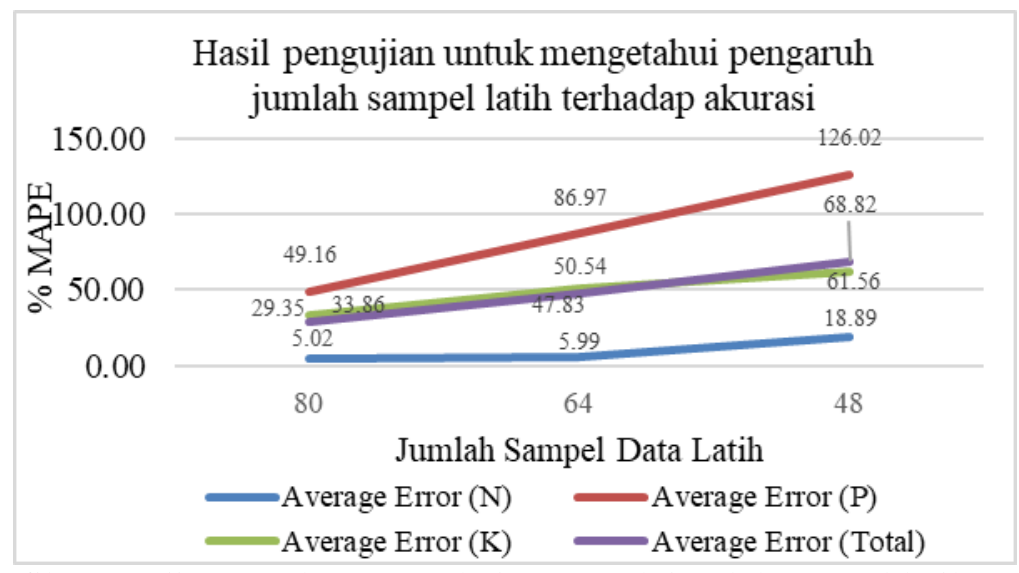

Gambar 9 Grafik pengujian untuk mengetahui pengaruh jumlah sampel latih terhadap akurasi

Pengujian tahap kelima untuk mengukur waktu komputasi sistem, terbagi menjadi dua, yakni perhitungan saat sistem mengambil citra data uji dengan kamera dan saat sistem mengambil citra data uji dari galeri. Perhitungan dimulai saat citra terambil hingga prediksi nilai unsur NPK keluar. Pengujian ini dilakukan dengan menggunakan smartphone Samsung Galaxy S6 Edge. Rata-rata waktu komputasi sistem selama 605,7 ms dengan waktu komputasi maksimal selama $831 \mathrm{~ms}$.

Tampilan aplikasi yang telah dibuat meliputi tampilan kamera, load galeri, hasil deteksi unsur, dan rekomendasi pupuk tercantum pada Gambar 10. Berdasarkan Gambar 10 (a) memuat tampilan menu kamera berfungsi untuk akuisisi citra dengan menggunakan kamera. Gambar 10 (b) memuat citra yang telah dipilih dari galeri beserta informasi mengenai citra tersebut meliputi lokasi direktori citra, ukuran citra, waktu dan tanggal pengambilan citra, serta koordinat GPS pengambilan citra. Gambar 10 (c) memuat hasil prediksi unsur NPK. Gambar 10 (d) memuat rekomendasi pemupukan dengan mengacu pada rumus pemupukan [8]. 


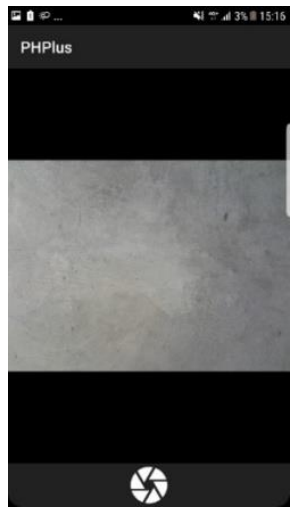

a)

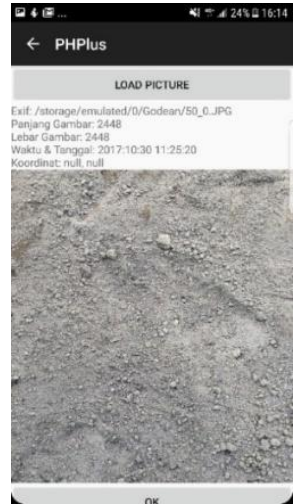

b)

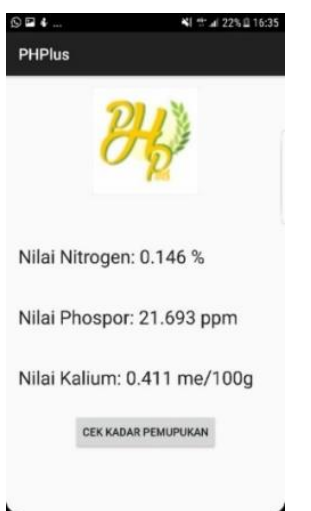

c)

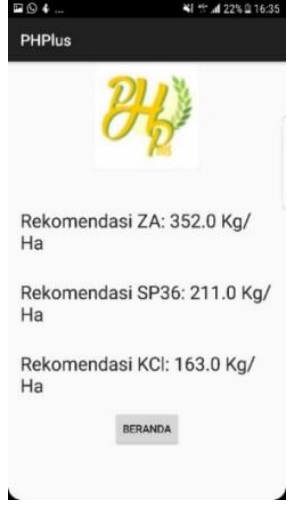

d)

Gambar 10 Tampilan hasil sistem

\section{KESIMPULAN}

Hasil pengujian menunjukkan bahwa sistem yang diusulkan dapat melakukan pendeteksian kadar unsur hara Nitrogen, Fosfor, dan Kalium (NPK) pada Tanah Persawahan di Daerah Istimewa Yogyakarta serta memberikan saran pemupukan berdasarkan formula LPT Bogor dengan akurasi pendeteksian rata-rata 70,65\% (N 94,98\%, P 50,84\%, dan K 66,14\%). Akurasi tersebut didapat dari pengambilan citra pada ketinggian optimal 70 dan sudut optimal $0^{\circ}$ terhadap permukaan tanah. Proses pada sistem berlangsung sangat cepat dengan waktu komputasi rata-rata selama 605,7 ms dan waktu komputasi maksimal selama $831 \mathrm{~ms}$. Toleransi ketinggian mencapai $-20 \mathrm{~cm}$ dengan rata-rata selisih MAPE hanya sebesar 3,62\%. Toleransi sudut mencapai $\pm 20^{\circ}$ dengan rata-rata selisih MAPE pada $\pm 10^{\circ}$ sebesar $3,13 \%$ dan pada $\pm 20^{\circ}$ sebesar $6,90 \%$.

\section{SARAN}

Beberapa saran yang dapat diberikan adalah diperlukan penelitian lebih lanjut untuk meningkatkan akurasi pengukuran kadar unsur NPK pada tanah persawahan dan penambahan lokasi lain sebagai tambahan data latih untuk meningkatkan akurasi pengukuran kadar unsur NPK pada tanah persawahan. Untuk meningkatkan akurasi ketinggian dan sudut, serta untuk mengurangi subjektifitas akibat pengamatan mata manusia, diperlukan penambahan fitur penampil sudut kemiringan (yaw, pitch, dan roll) dan heading dengan memanfaatkan sensor accelerometer, gyroscope, dan magnetometer pada smartphone, serta penelitian fitur penampil ketinggian dengan memanfaatkan sensor altitudemeter GPS atau membuat sistem odometri dengan memanfaatkan accelerometer dan gyroscope pada smartphone. 


\section{DAFTAR PUSTAKA}

[1] Badan Pusat Statistik, 2017, Provinsi Daerah Istimewa Yogyakarta Dalam Angka 2017, BPS Provinsi DIY, Yogyakarta.

[2] R. Amat, J. Y. Sari, and I. P. Ningrum, "Implementasi Metode Local Binary Patterns untuk Pengenalan Pola Huruf Hiragana dan Katakana pada Smartphone," JUTI: Jurnal Ilmiah Teknologi Informasi, no 2, vol. 15 - Juli 2017, pp 162-172, 2017 [Online]. Available: http://juti.if.its.ac.id/index.php/juti/article/viewFile/612/344. [Accessed: 12October-2017]

[3] Z. Pasongli, 2013, Identifikasi Seseorang Berdasarkan Citra Pembuluh Darah Menggunakan Ekstraksi Fitur Local Binary Pattern, Thesis, Jurusan Teknik Elektro, Universitas Kristen Maranatha, Bandung, [Online]. Available: http://repository.maranatha.edu/7908/. [Accessed: 08-December-2017]

[4] E. Acar and M. S. Özerdem, "The Texture Feature Extraction of Mardin Agricultural Field Images by HOG Algorithms and Soil Moisture Estimation based on the Image Textures," $23^{\text {th }}$ Signal Processing and Communications Applications Conference (SIU), pp 665-665, 2015 [Online]. Available: http://www ieeexplore.ieee.org/document/7129912. [Accessed: 02-February-2018]

[5] Riyanto, 2017, Filtering [Online]. Available: http://riyanto.lecturer.pens.ac.id/citrabab6.pdf. [Accessed: 22-February-2018]

[6] S. Firmansyah, D. Lelono, and R. Sumiharto, "Implementasi Pengolahan Citra Digital Sebagai Pengukur Nilai Resistor Pada Sistem Pemindai Resistor Berbasis Android," IJEIS (Indonesian J. Electron. Instrum. Syst., vol. 5, no. 1, p. 1, 2015 [Online]. Available: https://jurnal.ugm.ac.id/ijeis/article/view/7148/5596. [Accessed: 16February-2018]

[7] D. Rahmawati, A. Harjoko, and R. Sumiharto, "Purwarupa Sistem Tracking Sungai Menggunakan Unmanned Aerial Vehicle," IJEIS (Indonesian J. Electron. Instrum. Syst., vol. 3, no. 2, pp. 2088-3714, 2013 [Online]. Available: https://jurnal.ugm.ac.id/ijeis/article/view/3890/3179. [Accessed: 22-January-2018]

[8] LPT Bogor, 2014, Aplikasi Perhitungan Rekomendasi Pemupukan Menggunakan Nomograf Analisa Tanah, LPT, Bogor.

[9] R. Kurniawan and B. Yuniarto, 2016, Analisis Regresi: Dasar dan Penerapannya dengan R, Edisi Pertama, Kencana, Jakarta.

[10] W. Widiarso, 2010, Catatan Pada Uji Linearitas Hubungan [Online]. Available: http://www.widhiarso.staff.ugm.ac.id/files/widhiarso_2010_-

_uji_linearitas_hubungan.pdf. [Accessed: 08-May-2017]

[11] Sudaryono, 2014, Teori dan Aplikasi dalam Statistik, Penerbit ANDI, Yogyakarta. 